\title{
Rehabilitative treatment of cleft lip and palate: experience of the Hospital for Rehabilitation of Craniofacial Anomalies - USP (HRAC-USP) - Part 3: Oral and Maxillofacial Surgery
}

José Alberto de Souza FREITAS ${ }^{1}$, Daniela Gamba GARIB², Ivy Kiemle TRINDADE-SUEDAM ${ }^{3}$, Roberta Martinelli CARVALHO $^{4}$, Thais Marchini OLIVEIRA ${ }^{5}$, Rita de Cássia Moura Carvalho LAURIS ${ }^{6}$, Ana Lúcia Pompéia Fraga de ALMEIDA ${ }^{7}$, Lucimara Teixeira das NEVES ${ }^{8}$, Renato Yassutaka Faria YAEDÚ ${ }^{9}$, Simone SOARES ${ }^{7}$, Reinaldo MAZZOTTINI ${ }^{10}$, João Henrique Nogueira PINTO ${ }^{11}$

\footnotetext{
1- DDS, MSc, PhD, Superintendent, Hospital for Rehabilitation of Craniofacial Anomalies (HRAC); Full Professor, Department of Stomatology, Bauru School of Dentistry, University of São Paulo, Bauru, SP, Brazil.

2- DDS, MSc, PhD, Associate Professor of Orthodontics, Department of Pediatric Dentistry, Orthodontics and Community Health, Bauru School of Dentistry; Hospital for Rehabilitation of Craniofacial Anomalies (HRAC), University of São Paulo, Bauru, SP, Brazil.

3- DDS, MSc, PhD, Assistant Professor, Department of Biological Sciences, Bauru School of Dentistry and Laboratory of Physiology, Hospital for Rehabilitation of Craniofacial Anomalies (HRAC), University of São Paulo, Bauru, SP, Brazil.

4- DDS, MSc, PhD, Maxillofacial Surgeon, Dental Division of the Hospital for Rehabilitation of Craniofacial Anomalies (HRAC), University of São Paulo, Bauru, SP, Brazil.

5- DDS, MSc, PhD, Assistant Professor, Department of Pediatric Dentistry, Orthodontics and Community Health, Bauru School of Dentistry; Hospital for Rehabilitation of Craniofacial Anomalies (HRAC), University of São Paulo, Bauru, SP, Brazil.

6- DDS, MSc, Orthodontist, Dental Division of the Hospital for Rehabilitation of Craniofacial Anomalies (HRAC), University of São Paulo, Bauru, SP, Brazil. 7- DDS, MSc, PhD, Assistant Professor, Department of Prosthodontics, Bauru School of Dentistry; Hospital for Rehabilitation of Craniofacial Anomalies (HRAC), University of São Paulo, Bauru, SP, Brazil.

8- DDS, MSc, PhD, Assistant Professor, Department of Biological Sciences, Bauru School of Dentistry; Hospital for Rehabilitation of Craniofacial Anomalies (HRAC), University of São Paulo, Bauru, SP, Brazil.

9- DDS, MSc, PhD, Assistant Professor, Department of Stomatology, Bauru School of Dentistry; Hospital for Rehabilitation of Craniofacial Anomalies (HRAC), University of São Paulo, Bauru, SP, Brazil.

10- DDS, MSc, PhD, Associate Professor, Department of Stomatology, Bauru School of Dentistry and Dental Division of the Hospital for Rehabilitation of Craniofacial Anomalies (HRAC), University of São Paulo, Bauru, SP, Brazil.

11- DDS, MSc, PhD, Prosthodontist, Dental Division of the Hospital for Rehabilitation of Craniofacial Anomalies (HRAC), University of São Paulo, Bauru, SP, Brazil.
}

Corresponding address: Daniela Gamba Garib - Faculdade de Odontologia de Bauru - USP - Alameda Dr. Octávio Pinheiro Brizolla, 9-75 - Bauru - SP 17012-901 - Brazil - Phone: 55-14-3235-8217 - e-mail: dgarib@uol.com.br

Received: May 15, 2012 - Modification: June 27, 2012 - Accepted: July 02, 2012

\section{ABSTRACT}

\begin{abstract}
This paper presents the treatment protocol of maxillofacial surgery in the rehabilitation process of cleft lip and palate patients adopted at HRAC-USP. Maxillofacial surgeons are responsible for the accomplishment of two main procedures, alveolar bone graft surgery and orthognathic surgery. The primary objective of alveolar bone graft is to provide bone tissue for the cleft site and then allow orthodontic movements for the establishment of an an adequate occlusion. When performed before the eruption of the maxillary permanent canine, it presents high rates of success. Orthognathic surgery aims at correcting maxillomandibular discrepancies, especially anteroposterior maxillary deficiencies, commonly observed in cleft lip and palate patients, for the achievement of a functional occlusion combined with a balanced face.
\end{abstract}

Key words: Cleft palate. Cleft lip. Bone transplantation. Orthognathic surgery. 


\section{INTRODUCTION}

Maxillofacial surgery is involved throughout the rehabilitation process of cleft lip and palate, conducting minor procedures such as extractions, orthodontic traction, diagnosis and treatment of oral lesions and surgically assisted rapid maxillary expansion, as well as the two main procedures, i.e., alveolar bone graft, which main objective is to provide bone tissue for the clef site, ideally performed from 9 to 12 years of age, and orthognathic surgery, performed at the end of facial growth for the correction of maxillomandibular discrepancies, usually observed in patients with cleft lip and palate.

The purpose of alveolar bone grafting is to fill the alveolar bone cleft $^{6}$, support the alar base ${ }^{16,25}$, eliminate oronasal fistulas ${ }^{5,8}$, increase maxilla stability $^{1}$, allow the eruption of teeth into the grafted area $^{4}$, support the teeth adjacent to the cleft ${ }^{17}$, improve nasal symmetry ${ }^{29}$, and permit the orthodontic movement and the placement of osseointegrated implants, when indicated ${ }^{1-3}$. In turn, the goal of orthognathic surgery is to correct moderate and severe sagittal maxillomandibular discrepancies that could not be treated during the growth period by orthopedic or compensatory orthodontic treatment.

This paper describes the treatment protocol involving the specialty of maxillofacial surgery during the rehabilitation process of cleft lip and palate at the Hospital for Rehabilitation of Craniofacial Anomalies (HRAC-USP).

\section{ALVEOLAR BONE GRAFT PROCEDURE}

The period in which bone graft surgery is performed is of particular interest and is one of the main points for the achievement of good surgical outcomes. In the classic study of Boyne

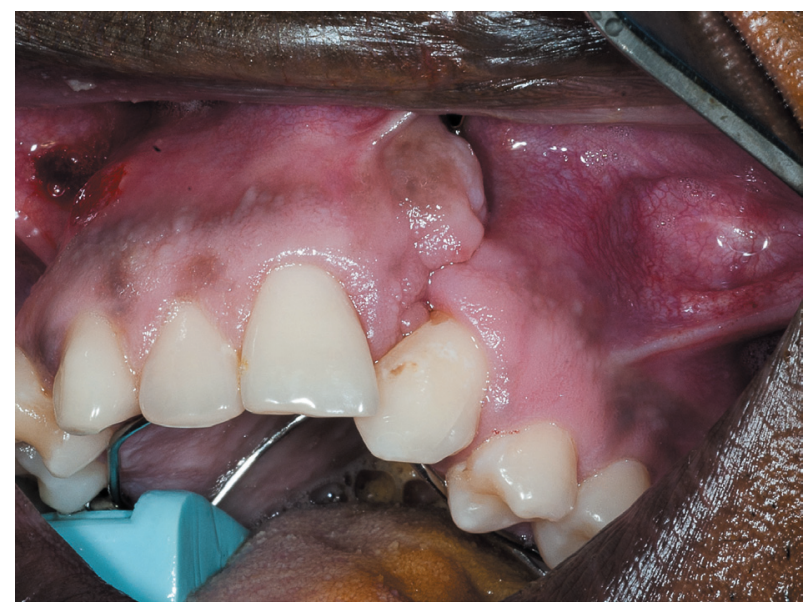

Figure 1- Occlusal view showing the aligment of the maxillary segments and Sands (1972), alveolar bone grafting surgery was classified according to the chronological age of the patient: 1) primary bone graft: performed in patients under 2 years of age; 2 ) early secondary bone graft: performed in patients aged 2 to 5 years; 3) secondary bone graft: between 6 and 15 years of age, and, 4) late secondary bone grafting: in individuals with complete dental and skeletal development. Silva Filho et al (1995) ${ }^{26}$, in turn, classified the bone graft surgery primarily according to the age of dental development: 1) primary alveolar bone graft: performed in the early childhood, around 1 year of age, along with the surgical repair of the palate, before the deciduous teeth have erupted completely; 2) secondary alveolar bone graft, performed along the mixed dentition, between 6 and 12 years of age. It may be subdivided into: a) early secondary: performed between 5 and 6 years of age, b) secondary: performed before the eruption of the permanent canine, between 8 and 12 years, c) late secondary: performed after the eruption of the permanent canine, approximately at age 12 , and, finally, 3) tertiary alveolar bone graft, performed in adulthood, around 18 years of age.

It is important to mention that scientific evidence ${ }^{6}$ have shown that primary alveolar bone graft surgery can impair maxillary growth leading to the development of malocclusions, including anterior and posterior crossbites. For this reason, the secondary alveolar bone graft, as described by Boyne and Sands $(1972)^{6}$ is the procedure elected by HRAC-USP as one of the important therapeutic stages for the rehabilitation of patients with cleft lip and palate. It has been performed routinely since 1992 when the Oslo team visited HRAC-USP, in order to teach and train the maxillofacial surgeons. It is our understanding that, when performed before the eruption of the maxillary canines, secondary alveolar bone graft allows great periodontal support

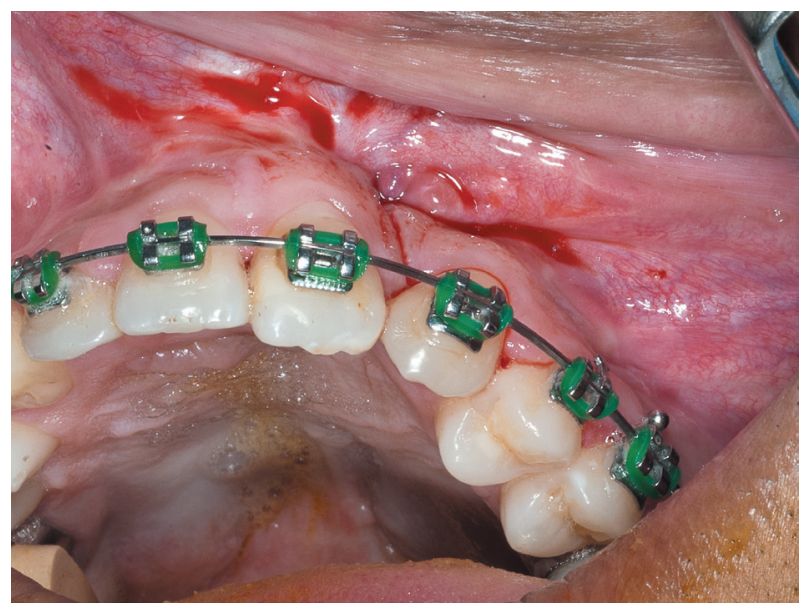

Figure 2- Preoperative view of the alveolar cleft showing the adequate keratinized mucosa 
for the eruption and preservation of the teeth adjacent to the cleft with no interference in facial development ${ }^{1}$. Furthermore, permanent canine tooth eruption promotes an intrinsic stimulus on the grafted bone, an essential factor for preventing resorption and maintaining bone level during bone healing ${ }^{30}$.

However, some procedures must be performed and some clinical details must be observed before bone grafting in order to obtain good surgical outcomes, as follows: 1) the correction of maxillary arch constriction by means of maxillary expansion is necessary before surgery in most of the cases ${ }^{13,14}$.

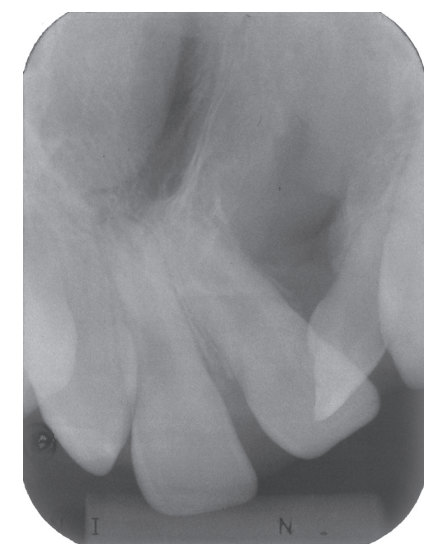

Figure 3- Pre-bone graft radiography
The objective of maxillary expansion is not only to treat the posterior crossbite, but also to align the maxillary segments, increasing the alveolar cleft width and, consequently, creating enough space for bone graft placement. Additionally, it facilitates the transoperative maneuvers for nasal mucosa lifting and its suture before the graft is placed (Figure 1); 2 ) Diagnose the presence of premature contact in the premaxilla, especially in bilateral clefts. These contacts mobilize the premaxilla and impair bone formation after the graft; 3) Presence of erupted or partially erupted teeth at the cleft area complicates the handling and suturing of soft tissue after the bone graft. Erupted supernumerary teeth located at the cleft borders should be extracted 4 months before surgery in cases where there is no space in the arch. In late secondary alveolar bone graft cases, maxillary canines should be orthodontically moved if they erupted much too close to cleft borders, impairing the suture procedures and the accommodation of the bone graft; 4) Unerupted lateral incisor distal to cleft can be extracted during surgery, for orthodontic purposes, if indicated. Special attention should be given to trans-surgical extraction since it may increase the dimension of the oronasal fistula or even lacerate the nasal mucosa, making it difficult to stabilize the bone graft transoperatively; 5) Gengival graft should be performed before bone graft procedure for maxillary
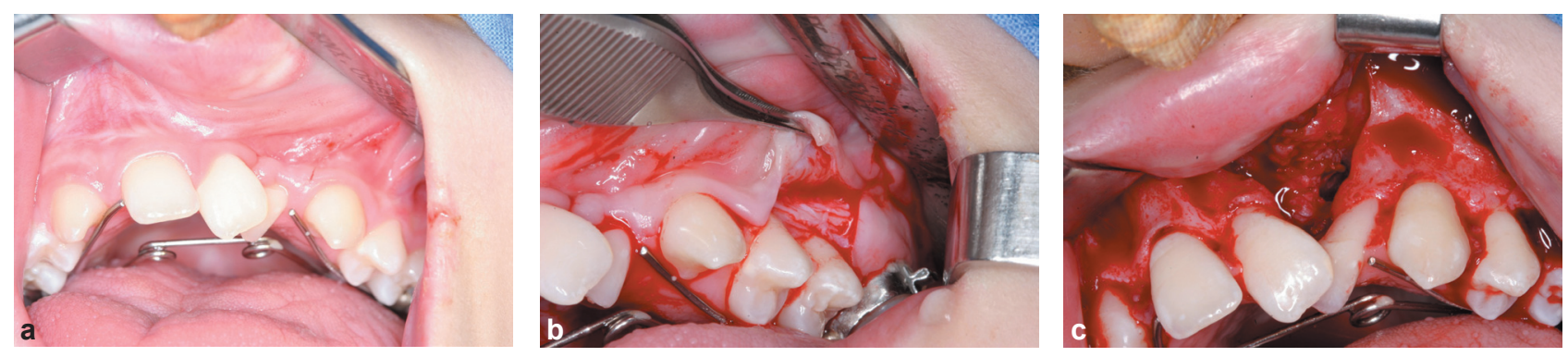

Figure 4- Secondary alveolar bone graft procedure performed in a unilateral cleft (left side). (a) Pre-incision intraoral view. (b) Incision. (c) Alveolar cleft

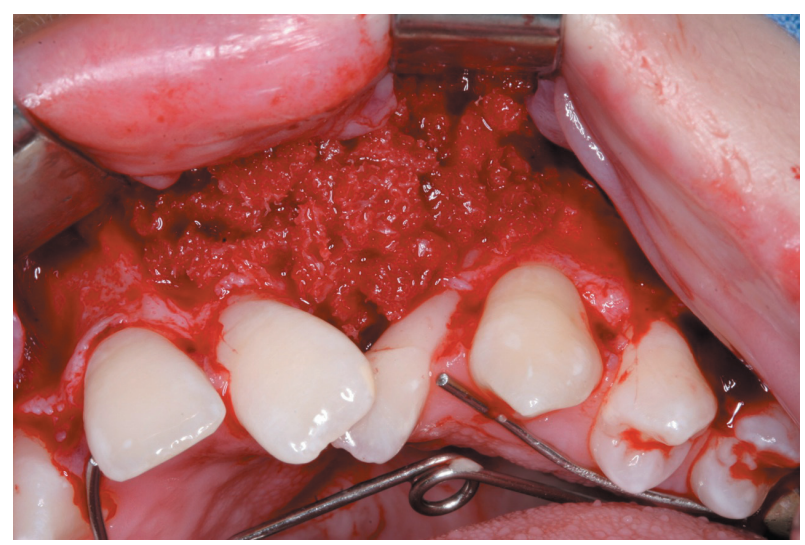

Figure 5- Placement of cancellous bone from the iliac crest

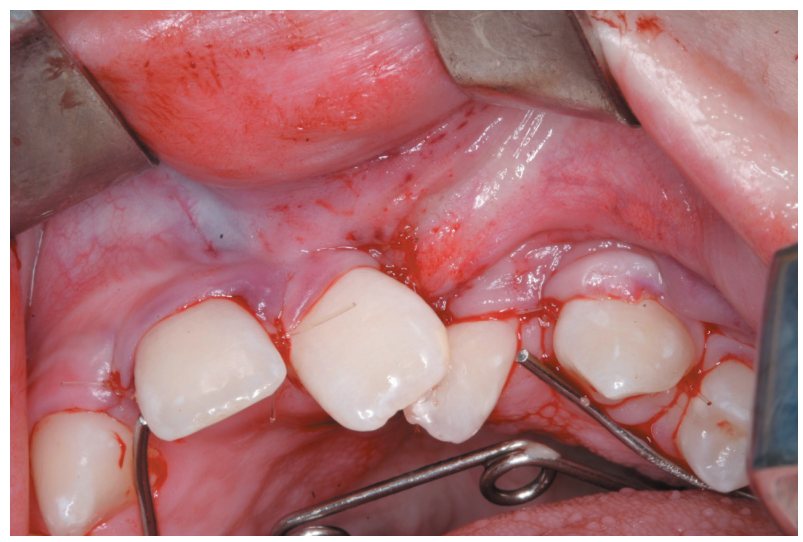

Figure 6- Final suture 
anterior teeth with a thin or absent keratinized mucosa. This procedure optimizes the periodontal postoperative hygiene, and, 6) Evaluating the alveolar cleft width and the quantity and quality of the buccal and palatal mucosa is necessary (Figure 2). Available soft tissue should be sufficient to be rotated covering the entire graft region without soft tissue tension.

Autogenous bone is still considered the gold standard material for filling the alveolar cleft. Bone marrow is preferred instead of the cortical bone

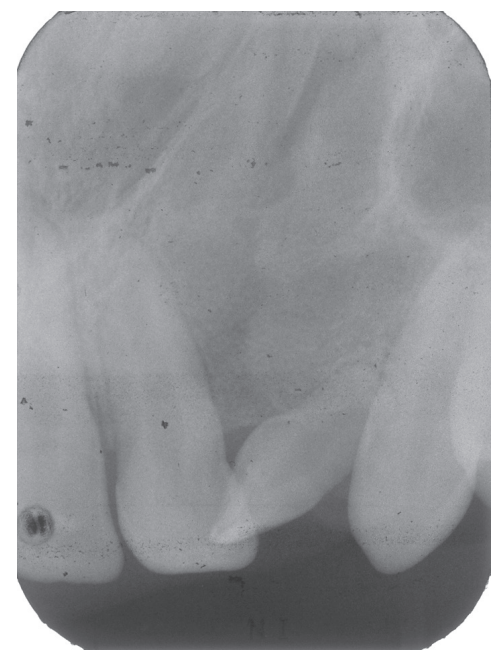

Figure 7- Postoperative radiography
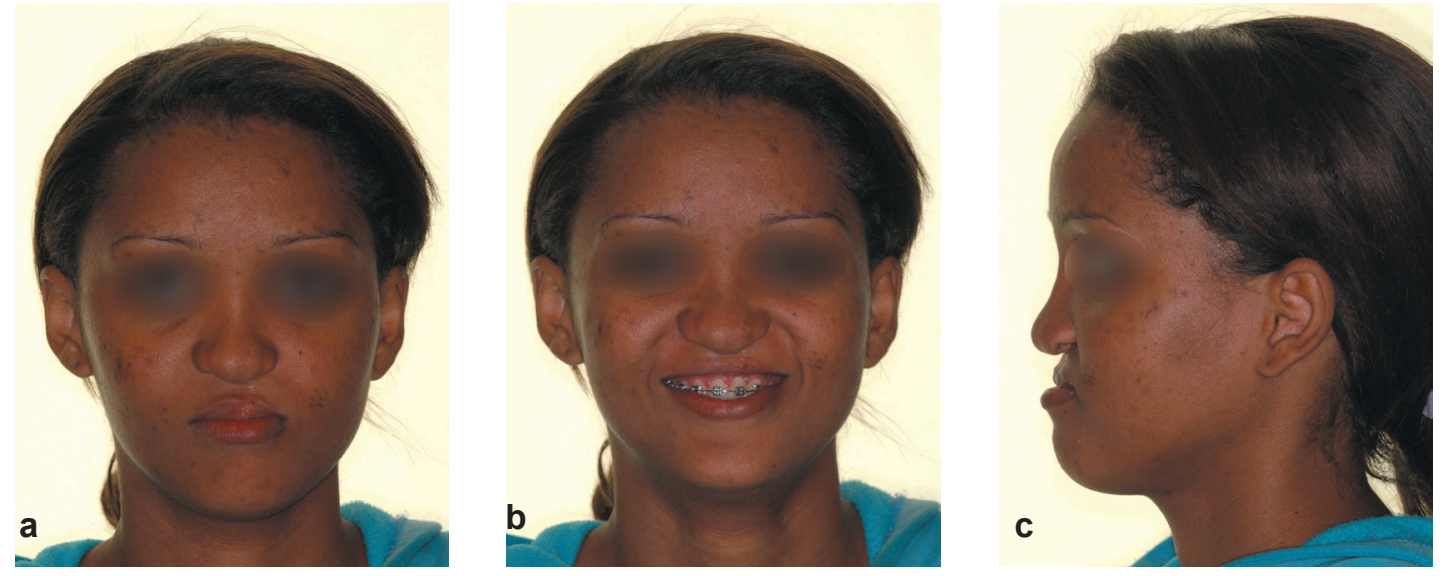

Figure 8- Preoperative photographs of a patient with complete unilateral cleft lip and palate treated with orthognatic surgery (a) Front preoperative photograph; (b) Smile preoperative photograph and (c) Profile preoperative photograph
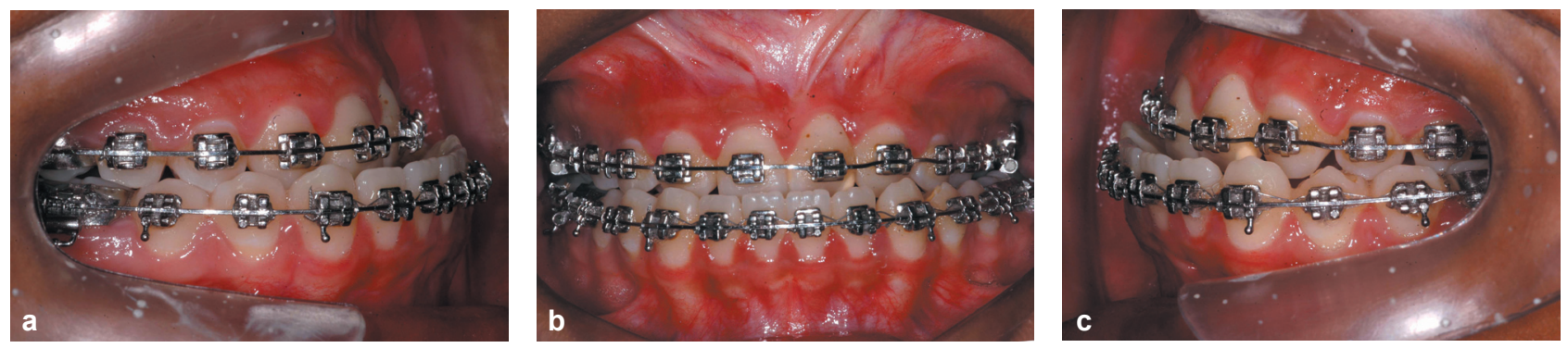

Figure 9- Preoperative intraoral photographs (a) right occlusion view, (b) frontal view, (c) left view 
even better surgical outcomes can be achieved. Due to the data obtained, the authors suggest that bone engineering science might have found a path to a promising bone substitute.

The success of secondary bone graft is directly
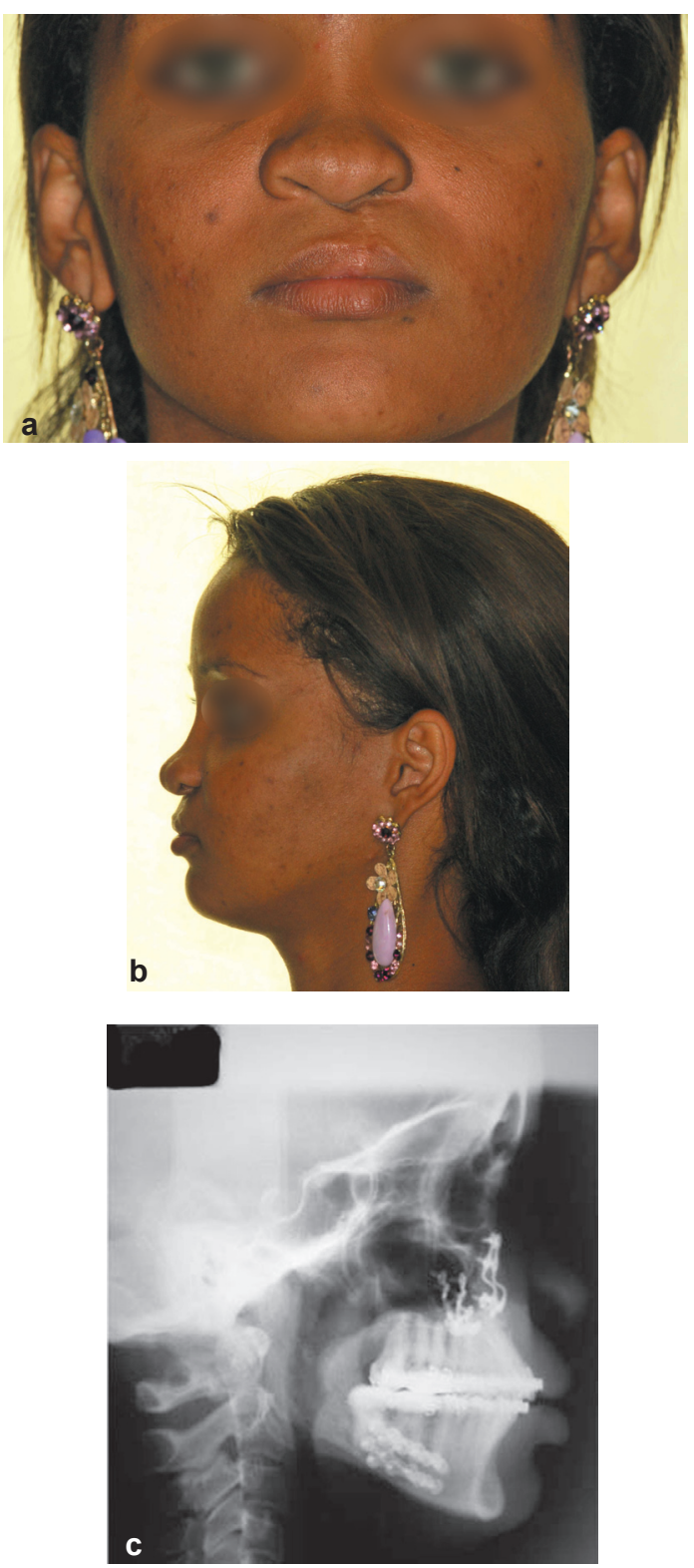

Figure 10-Le Fort I osteotomy with maxillary advancement was performed. Postoperative photographs are shown (a) facial frontal view (b) facial lateral view (c) post-surgical cephalometric radiography related to pre-graft orthodontic preparation ${ }^{2,8}$, careful surgical manipulation of the soft tissue and maintenance of oral hygiene postoperatively (Figure 4, 5, 6). Trindade, et al. (2005) assessed the outcomes of secondary alveolar bone grafts using autogenous bone in patients with complete unilateral cleft lip and palate operated before eruption of the permanent canine in a sample from HRAC-USP, by means of radiographic analysis. Eighty six percent of the cases were classified as successful outcomes and canine eruption was observed in $95 \%$ of the cases operated 4 years before the study. The authors concluded that when alveolar bone graft is performed before canine eruption it can be considered a procedure with a high rate of success.

On the other hand, Trindade-Suedam et al (2012) assessed the outcome of the alveolar bone graft, using autogenous bone, by means of cone beam computed tomography. Outcome assessment was performed according to the timing of surgery: secondary alveolar bone grafting (SABG), undertaken during mixed dentition and tertiary alveolar bone grafting (TABG), undertaken during permanent dentition. In the SABG group, 6 to 12 months postoperatively, $75 \%$ of the patients were classified as having excellent/good conditions and $25 \%$ as having regular/bad conditions. No patients were observed as having failure conditions. In the TABG group, $53 \%$ of the patients were classified as having excellent/good, 21\% were classified as having regular/bad conditions, and $26 \%$ were classified as having failure conditions. Significantly better outcomes were observed for the SABG group when compared with the TABG group. In conclusion, the age in which $A B G$ is performed is a factor that impacts on the surgical outcome and increasing age is associated with worse outcomes.

After graft surgery, the patient remains hospitalized for 4 days for oral hygiene instructions and postoperative control. The clinical and radiographic follow-up is performed after 60 days of surgery and, if there was bone formation, the orthodontic treatment is initiated. If the amount of bone formed is not sufficient for orthodontic movement, an additional 60-day period is necessary for revaluation (Figure 7 ).

The major complications of this procedure
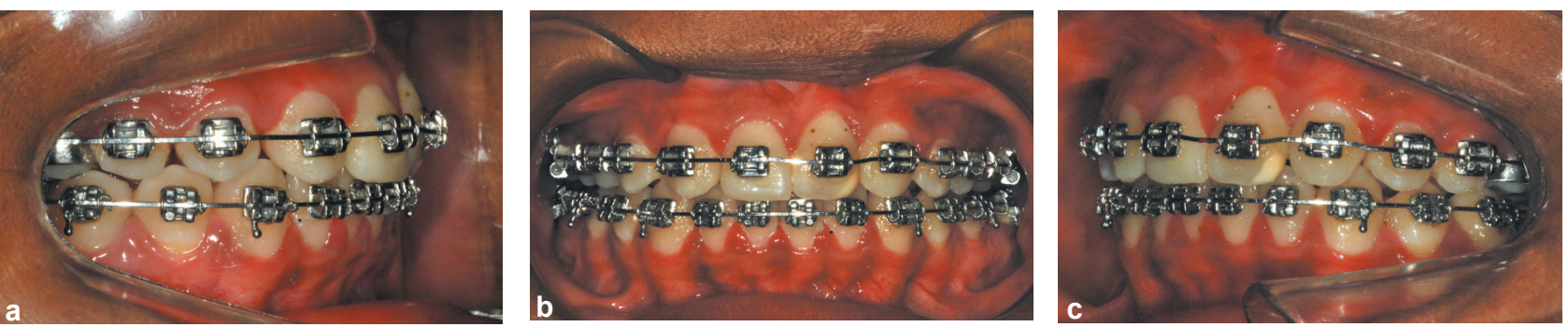

Figure 11- Postoperative intraoral photographs (a) right view (b) frontal view (c) left view 
include resorption of bone graft, suture dehiscence, tissue necrosis, especially in the palatal area, and graft contamination. These complications can be observed more frequently when alveolar bone graft is performed after maxillary canine eruption, mainly in complete alveolar clefts and wider defects. It seems that there is an ischemia in the most central portion of the bone graft and, then, tissue necrosis is observed. Vertical (height) and horizontal (thickness) bone resorptions can be observed especially in late secondary alveolar grafts, large bone defects and severe maxillary vertical deficiency. When these events occur it is important to consider if it is worthwhile performing alveolar bone graft again or if a conventional prosthesis would fit well.

\section{ORTHOGNATHIC SURGERY}

The rehabilitation of cleft lip and palate is a process initiated early in life. The surgical procedures for rehabilitation comprise primary lip and palate repair. These surgical procedures provide clear benefits for facial esthetics and function. However, the primary plastic surgeries have a restrictive effect on maxillary growth in patients with complete cleft lip and palate $e^{23,31}$.

Within this context, orthognathic surgery aims at correcting skeletal facial deformities present in early adulthood. The orthognatic surgery is indicated to patients with moderate to severe maxillary deficiency after growth (anteroposterior arch relation Goslon 4 and 5). Mild maxillary deficiencies (Goslon 3) with acceptable facial esthetics are treated with orthodontic tooth compensations. After the alveolar bone graft procedure, the maxilla can be advanced as a single structure, reducing the risks of an ischemia at maxillary segments edges.

Yet, unofficial data suggest that approximately $40 \%$ of the patients with complete cleft lip and palate at HRAC-USP undergo orthognathic surgery, especially maxillary advancement surgery or combined maxillary advancement and mandibular retroposition. In these cases the amount of maxillary advancement required are considered clinically large, usually around $15 \pm 5 \mathrm{~mm}$, with lower repositioning of around $4 \mathrm{~mm}$, and, therefore, partial relapses are somehow frequent.

Orthognathic surgery planning is performed using: 1) Post-orthodontic dental casts: at this stage, the patient is analyzed as to the orthodontic preparation and final occlusion, addressing the anteroposterior, transverse and vertical discrepancies; 2) Frontal and profile facial analysis: this is always performed with the patient in natural head positioning, relaxed lips and condyles seated in the fossa. The patient must be assessed for facial symmetry and harmony with relaxed lips and during smiling (Figure 8, 9); 3) Temporomandibular and mastication muscles analysis: evaluation of mandibular movement, presence of pain, TMJ and masticatory muscles disorders is essential to analyze pre-surgical status and the surgical outcomes after restoration of a functional and stable occlusion; 4) Cephalometric tracing: after dental cast and facial analysis, cephalometric tracing is performed to measure the planned skeletal movements; the cephalometric tracing can be performed on a lateral cephalogram or computed tomography. Importantly, the examination should be performed with the patient using an occlusal record, condyles seated in the fossa, relaxed lips and natural head positioning; 5) Dental cast surgery: this is the last stage of the surgical planning and involves transfer of information from all clinical assessments to the dental cast. This should always be performed with the dental casts mounted on a semi-adjustable articulator with the occlusal records obtained from facial analysis and radiographs. It is recommended to perform dental cast surgery in an Erickson platform to minimize errors in the transfer of movements of skeletal cephalometric tracing to the models. At the end of planning, a surgical guide is obtained to position the intermediate segments (maxilla or mandible) in the correct position relative to the other segment in the original position. After surgical planning, the next step is the surgical procedure. The osteotomies are maxillary Le Fort I and mandibular sagittal osteotomy. This allows achievement of tridimensional skeletal movements for both the maxilla and mandible.

The patient remains hospitalized for 4 to 5 days until it is possible to maintain a good hygiene and the patient is able to change the intermaxillary orthodontic elastics correctly. The clinical and radiographic postoperative follow-up are performed at every 60 days during the first 6 months and then at every 6 months for at least 2 years.

The success of orthognathic surgery begins with proper orthodontic preparation, careful planning, precise surgical technique and postoperative care with diet and oral hygiene (Figure 10, 11). The major complications include maxillary relapse and mobility due to great advances as a consequence of severe midface deficiency, usually observed in cleft lip and palate patients, an adverse effect of primary plastic surgeries. In order to prevent maxillary relapses and minimize respiratory and aesthetic problems durind adolescence, osteogenic distraction can be considered prior to orthognathic surgery, for extreme anteroposterior discrepancies. It can be performed from 9-10 years of age, depending on maxillary canine germ position to allow Le Fort I osteotomy, without its downfracture. 


\section{FINAL CONSIDERATIONS}

Maxillofacial surgery is an important field in the rehabilitation of cleft lip and palate. The role of maxillofacial surgery at our center is to perform the secondary alveolar bone graft procedure and the orthognatic surgeries. Alveolar bone graft procedure reconstructs the alveolar bone morphology, permitting tooth movement at the maxillary anterior region. The orthognatic surgery is indicated for patients with complete cleft lip and palate and moderate to severe maxillary deficiency and generally evolves le Fort I maxillary advancement.

\section{REFERENCES}

1- Abyholm FE, Bergland O, Semb G. Secondary bone grafting of alveolar clefts. A surgical/orthodontic treatment enabling a nonprosthodontic rehabilitation in cleft lip and palate patients. Scand J Plast Reconstr Surg. 1981;15(2):127-40.

2- Amanat N, Langdon JD. Secondary alveolar bone grafting in clefts of the lip and palate. J Craniomaxillofac Surg. 1991;19(1):714.

3- Bergland O, Semb G, Abyholm F, Borchgrevink H, Eskeland G. Secondary bone grafting and orthodontic treatment in patients with bilateral complete clefts of the lip and palate. Ann Plast Surg. $1986 ; 17(6): 460-74$.

4- Bergland O, Semb G, Abyholm FE. Elimination of the residual alveolar cleft by secondary bone grafting and subsequent orthodontic treatment. Cleft Palate J. 1986;23(3):175-205.

5- Boyne PJ, Sands NR. Combined orthodontic-surgical management of residual palato-alveolar cleft defects. Am J Orthod. $1976 ; 70(1): 20-37$.

6- Boyne PJ, Sands NR. Secondary bone grafting of residual alveolar and palatal clefts. J Oral Surg. 1972;30(2):87-92.

7- Dempf R, Teltzrow T, Kramer FJ, Hausamen JE. Alveolar bone grafting in patients with complete clefts: a comparative study between secondary and tertiary bone grafting. Cleft Palate Craniofac J. 2002;39(1):18-25

8- Eldeeb ME, Hinrichs JE, Waite DE, Bandt CL, Bevis R. Repair of alveolar cleft defects with autogenous bone grafting: periodontal evaluation. Cleft Palate J. 1986;23(2):126-36.

9- Enemark H, Krantz-Simonsen E, Schramm JE. Secondary bonegrafting in unilateral cleft lip palate patients: indications and treatment procedure. Int J Oral Surg. 1985;14(1):2-10.

10- Enemark $H$, Sindet-Pedersen S, Bundgaard M. Long-term results after secondary bone grafting of alveolar clefts. J Oral Maxillofac Surg. 1987;45(11):913-9.

11- Eppley BL, Sclaroff A, Delfino JJ. Secondary management of the premaxilla in bilateral cleft lip and palate patients. J Oral Maxillofac Surg. 1986;44(12):987-98.

12- Freihofer HP, Borstlap WA, Kuijpers-Jagtman AM, Voorsmit $R A$, van Damme PA, Heidbüchel $K L$, et al. Timing and transplant materials for closure of alveolar clefts. A clinical comparison of 296 cases. J Craniomaxillofac Surg. 1993;21(4):143-8.

13- Freitas JA, Garib DG, Oliveira M, Lauris RC, Almeida AL, Neves $\mathrm{LT}$, et al. Rehabilitative treatment of cleft lip and palate: experience of the Hospital for Rehabilitation of Craniofacial Anomalies - USP (HRAC-USP) - Part 2: Pediatric Dentistry and Orthodontics. J Appl Oral Sci. 2012;20(2):272-85.

14- Freitas JA, Neves LT, Almeida AL, Garib DG, Trindade-Suedam IK, Yaedú RY, et al. Rehabilitative treatment of cleft lip and palate: experience of the Hospital for Rehabilitation of Craniofacial Anomalies/USP (HRAC/USP) - Part 1: overall aspects. J Appl Oral Sci. $2012 ; 20(1): 9-15$.
15- Hogeman KE, Jacobsson S, Sarnäs KV. Secondary bone grafting in cleft palate: a follow up of 145 patients. Cleft Palate J. $1972 ; 9(1): 39-42$.

16- Jackson IT, Vandervord JG, McLennan JG, Christie FB, McGregor JC. Bone grafting of the secondary cleft lip and palate deformity. Br J Plast Surg. 1982;35(3):345-53.

17- Kortebein MJ, Nelson CL, Sadove AM. Retrospective analysis of 135 secondary alveolar cleft grafts using iliac or calvarial bone. J Oral Maxillofac Surg. 1991;49(5):493-8.

18- Larson O, Ideberg M, Nordin KE. Early bone grafting in complete cleft lip and palate cases following maxillofacial orthopedics. IV. A radiographic study of the incorporation of the bone grafts. Scand J Plast Reconstr Surg. 1983;17(2):93-8.

19- Lazarou SA, Contodimos GB, Gkegkes ID. Correction of alveolar cleft with calcium-based bone substitutes. J Craniofac Surg. 2011;22(3):854-7.

20- Lilja J, Möller M, Friede H, Lauritzen C, Petterson LE, Johanson $B$. Bone grafting at the stage of mixed dentition in cleft lip and palate patients. Scand J Plast Reconstr Surg Hand Surg. 1987;21(1):73-9.

21- Marchac AC, Warren SM. Correction of alveolar cleft with calcium-based bone substitutes. J Craniofac Surg. $2011 ; 22(3): 858-9$.

22- Maxson BB, Baxter SD, Vig KW, Fonseca RJ. Allogeneic bone for secondary alveolar cleft osteoplasty. J Oral Maxillofac Surg. 1990;48(9):933-41.

23- Ross RB. Treatment variables affecting facial growth in complete unilateral cleft lip and palate. Cleft Palate J. 1987;24(1):5-77.

24- Sadove AM, Nelson CL, Eppley BL, Nguyen B. An evaluation of calvarial and iliac donor sites in alveolar cleft grafting. Cleft Palate J. 1990;27(3):225-8; discussion 229

25- Schultz RC. Cleft palate fistula repair. Improved results by the addition of bone. J Craniomaxillofac Surg. 1989;17(Suppl 1):34-6. 26- Silva Filho OG, Ferrari Junior FM, Capelozza Filho L, Albuquerque MVP. Enxerto ósseo alveolar em pacientes fissurados: realidade e perspectivas. Ortodontia. 1995; 28:34-45.

27- Sindet-Pedersen S, Enemark H. Mandibular bone grafts for reconstruction of alveolar clefts. J Oral Maxillofac Surg. 1988;46(7):533-7.

28- Strong SM. Adolescent dentistry: multidisciplinary treatment for the cleft lip/palate patient. Pract Proced Aesthet Dent. 2002;14(4):333-8; quiz 340,342.

29- Trindade IK, Mazzottini R, Silva Filho OG, Trindade IEK, Deboni $M C Z$. Long term radiographic asssessment of secondary alveolar bone grafting outcomes in patients with alveolar cleft. Oral Surg, Oral Med, Oral Pathol, Oral Radiol and Endod. 2005; 100(3):271-7. 30- Trindade-Suedam IK, da Silva Filho OG, Carvalho RM, de Souza Faco RA, Calvo AM, Ozawa TO, Trindade AS Jr, Trindade IE. Timing of alveolar bone grafting determines different outcomes in patients with unilateral cleft palate. J Craniofac Surg. 2012 Sep;23(5):1283-6.

31- Williams AC, Bearn D, Mildinhall S, Murphy T, Sell D, Shaw WC, et al. Cleft lip and palate care in the United Kingdom - the Clinical Standards Advisory Group (CSAG) Study. Part 2: dentofacial outcomes and patient satisfaction. Cleft Palate Craniofac J. $2001 ; 38(1): 24-9$. 